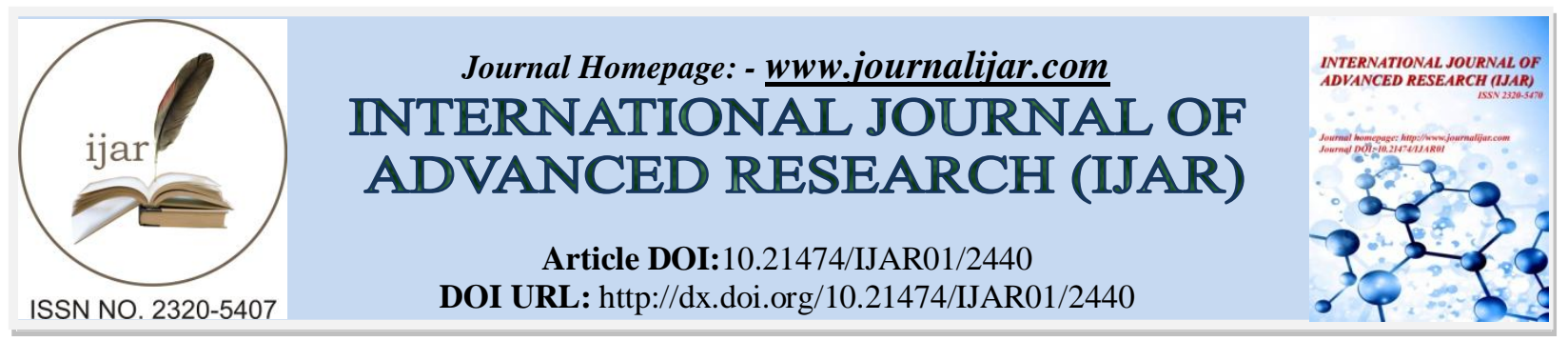

RESEARCH ARTICLE

\title{
AN EXPERIMENTAL AND SIMULATION ANALYSIS OF VOLTAGE REGULATOR USING THE MULTISIM.
}

C. M. Arunkumar ${ }^{1}$ and P. C. Mukesh Kumar ${ }^{2}$.

1. University College of Engineering, Pattukkottai.

2. University College of Engineering, Dindigul.

\section{Manuscript Info}

(.........................

Manuscript History

Received: 20 October 2016

Final Accepted: 22 November 2016

Published: December 2016

Key words:-

Multisim, LM7805,

Thermistor,Ultiboard

\section{Abstract}

Voltage regulators have been widely used in many electronic devices such as charger, CPU and TV, etc.Hence analysis the performance is very important to improve life time, less power consumption and to reduce heat dissipation also. Thethermal management of high heat fluxes is a serious issue in a higher performance of electronic devices. Inthis paper, the performance of voltage regulator was analyzed experimentally and then the simulation was carried out by Multisim Software.Multisim is an electronic circuit design program for schematic capture and simulation. The PCB layout design of linear voltage regulator circuit are designed using Ultiboard and the simulated output and waveform are obtained through Multisim. Multisim is the flexibility to design various complex circuits and pretest the circuit is possible before implementation.

Copy Right, IJAR, 2016,. All rights reserved.

\section{Introduction:-}

Multisim was developed by the Electronics Workbench Group in the company of National Instruments, and it's a software for simulating and designing electric circuits based on the Microsoft operating system. Both the analog and digital circuit design are possible. It can simulate real electric /electronics circuit experimental platform by using graphical operation interfaces. Multisim software was widely used for simulating, analyzing and designing of electric circuits. It promotes many editions, according to their designer need to perform the choices. This software reduces the modelling errors and also reduce the time of the development. It also significantly reduces the hardware and circuit debugging time massively. By using the Multisim simulation software, one cannot only know clearly the work status of the electric circuit, but can also measure is performance's indexes, providing a very convenient mean for understanding the design of electric circuits [1]-[5]

Voltage regulators are used to provide a stable power supply to the microprocessor. Voltage regulators are found nearly in all electronic systems. They are essential for delivering power from an energy source to integrated circuits at their respective and desired voltage levels. Now a day, there is a demand for smaller portable devices, so the size of voltage regulator also scaled down. Moreover, continues scaling need better power management for microprocessor design.Multisim is used to optimize circuit designs, minimize errors, and reduce prototyping iteration. This can improve the performance of designs by taking advantage of powerful simulation to identify errors earlier in the design flow and reduce costly prototype iterations [6].

Corresponding Author:- C. M. Arunkumar.

Address:-University College of Engineering,Pattukkottai. 


\section{Voltage Regulator:}

The Input voltage range for Voltage regulator is $7 \mathrm{~V}-35 \mathrm{~V}$, output current up to $1 \mathrm{~A}$ and operating Temperature 0 $+125^{\circ} \mathrm{C}$ these are the features of voltage regulator.

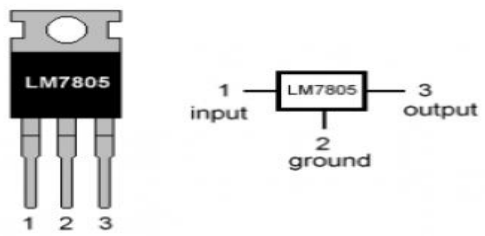

Fig 1:- IC7805 Voltage Regulator

The three pin are input GND, output as shown in fig 1. The electrical characteristics shown in table 1[7]

Table 1:- Electrical characteristics of LM7805.

\section{Electrical Characteristics (MC7805/LM7805)}

\begin{tabular}{|c|c|c|c|c|c|c|c|}
\hline \multirow{2}{*}{ Punmetar } & \multirow{2}{*}{ Symbal } & \multirow{2}{*}{\multicolumn{2}{|c|}{ Conditiana }} & \multicolumn{3}{|c|}{ mC780sum7oss } & \multirow{2}{*}{ Unt } \\
\hline & & & & Mhe & Type. & Mar. & \\
\hline \multirow[b]{2}{*}{ Output Velags } & \multirow[b]{2}{*}{ wo } & $T_{1}=+25^{\circ} \mathrm{C}$ & & 4.8 & 30 & 52 & \multirow[b]{2}{*}{$v$} \\
\hline & & \multicolumn{2}{|c|}{$\begin{array}{l}30 \mathrm{mh} \leq \mathrm{lo} \leq 1.0 \mathrm{~A}, \mathrm{PD}_{\mathrm{O}} \leq 15 \mathrm{~W} \\
\mathrm{~V}=7 \mathrm{~V} \text { io } 20 \mathrm{~W}\end{array}$} & 4.73 & 30 & 525 & \\
\hline \multirow{2}{*}{ Line Meguiation (Notal) } & \multirow{2}{*}{ Nogtin } & \multirow{2}{*}{$\mathrm{TJ}=+2 \mathrm{~s}^{\circ} \mathrm{C}$} & $\mathrm{VO}=7 \mathrm{~V}$ t $25 \mathrm{~V}$ & . & 40 & 100 & \multirow{2}{*}{$m v$} \\
\hline & & & $V=E V$ to $12 \mathrm{~V}$ & . & 18 & 30 & \\
\hline \multirow[b]{2}{*}{ Lasd Meguiribon (Nolw1) } & \multirow[b]{2}{*}{ Medoat } & \multirow[b]{2}{*}{$\mathrm{TJ}=+2 \mathrm{~s}^{\circ} \mathrm{C}$} & $10=5.0 \mathrm{mat}$ tol.sa & $\cdot$ & 0 & 100 & \multirow[b]{2}{*}{$m v$} \\
\hline & & & $\begin{array}{l}10=280 \mathrm{mh} \text { to } \\
750 \mathrm{~mA}\end{array}$ & $\cdot$ & 4 & 30 & \\
\hline Ouinecant Currert & 10 & $T_{J}=+2 s^{\circ} \mathrm{C}$ & & $\cdot$ & 50 & 80 & $\mathrm{~mA}$ \\
\hline \multirow{2}{*}{ Oulancent Currert Changen } & \multirow{2}{*}{ Q } & \multicolumn{2}{|c|}{$10=5$ ma to 1.04} &. & 0.03 & 0.5 & \multirow{2}{*}{$m A$} \\
\hline & & \multicolumn{2}{|c|}{$\mathrm{VP} F \mathrm{~N}$ is $25 \mathrm{~V}$} & . & 0.3 & 13 & \\
\hline Output Votapow Drit & $\Delta \mathrm{NO} / \mathrm{AT} T$ & \multicolumn{2}{|l|}{$10 \times 5 m A$} & . & .08 &. & $m m^{2}{ }^{\circ} \mathrm{C}$ \\
\hline Outped Nodie Vetay & WN & \multicolumn{2}{|c|}{$1=10$ arz io $100 \mathrm{CH} z, \mathrm{~T}_{A}=+2 \mathrm{~S}^{\circ} \mathrm{C}$} & $\cdot$ & 42 & $\cdot$ & MVNV \\
\hline Mrpple Mapidion & $\mathrm{Nm}$ & \multicolumn{2}{|c|}{$\begin{array}{l}f=1201 \mathrm{Ht} \\
\mathrm{V}_{0}=6 \mathrm{~V} \mathrm{~b}_{0} 18 \mathrm{~V}\end{array}$} & 62 & 73 & - & $\mathrm{AB}$ \\
\hline Dropout Votage & Vorop & \multicolumn{2}{|c|}{$10=1 \mathrm{~A} T_{\jmath}=+25^{\circ} \mathrm{C}$} & - & 2 & $\cdot$ & $\mathrm{v}$ \\
\hline Output Menistanca & 10 & \multicolumn{2}{|l|}{$1=10042$} & - & 15 & - & $m n$ \\
\hline Short Cresult Cumart & $B C$ & \multicolumn{2}{|c|}{$V I=35 V, T A=+28^{\circ} \mathrm{C}$} & . & 230 & - & $m A$ \\
\hline Peak Curment & DK & \multicolumn{2}{|c|}{ TJ $=2 s^{\circ} \mathrm{C}$} & . & 22 & . & A \\
\hline
\end{tabular}

\section{Line Regulation:-}

Line regulation is a measure of the ability of the power supply to maintain its output voltage given changes in the input line voltage. Line regulation is expressed as percent of change in the output voltage relative to the change in the input line voltage.

$$
\text { Line regulation }=\frac{\Delta \mathrm{V}_{\mathrm{O}}}{\Delta \mathrm{V}_{\mathrm{i}}}
$$

\section{Load Regulation:-}

Load regulation is the capability to maintain a constant voltage (or current) level on the output channel of a power supply despite changes in the supply's load (such as a change in resistance value connected across the supply output).

$$
\text { Load regulation; } \frac{\Delta \mathrm{V}_{\mathrm{O}}}{\Delta \mathrm{I}_{\mathrm{O}}}
$$

\section{Quiescent Current:-}

The quiescent current $\mathrm{I}_{q}$ is the difference between the input current $\mathrm{I}_{\mathrm{in}}$ and the output current. This current denotes the current drawn from the power supply when there is no load.

$$
I_{q}=I_{i}-I_{0}
$$




\section{Multisim:-}

NI Multisim is an electronic schematic capture and simulation program. With Multisim, the parameter optimization and simulation analysis for the electronic circuit design can be achieved [8].

\section{Simulation design of Voltage regulator:-}

More than 16,000 components are available to design the complex circuits.

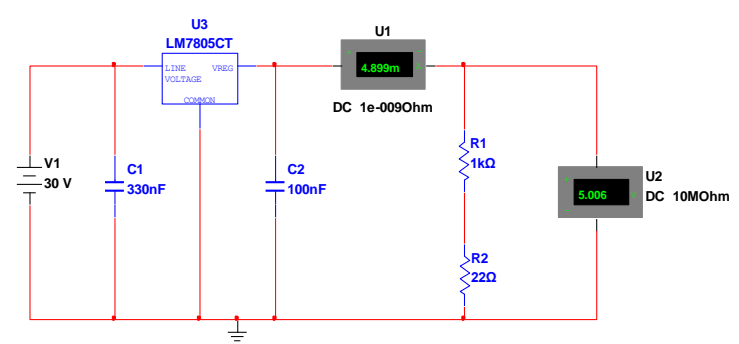

Fig 2:- Voltage regulator circuit using LM7805

The circuit consist of capacitor $C_{1}=300 \mathrm{nF}, C_{2}=100 \mathrm{nF}$ and series resistor $R_{1}=1 \mathrm{k} \Omega, R_{2}=220 \Omega$ are shown in fig2.

\section{Results and Discussion:-}

According to the optimum circuit parameters of the above simulation, the actual circuit was designed.

The quiescent current values are obtained by using simulation software shown in fig3.

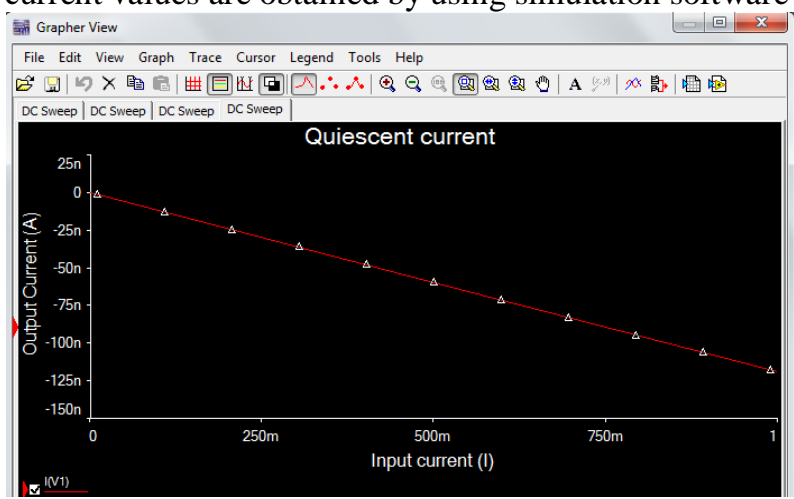

Fig 3:- Simulation output for current.

As shown in fig 4, the DC Transfer characteristic output also obtained using simulation software.

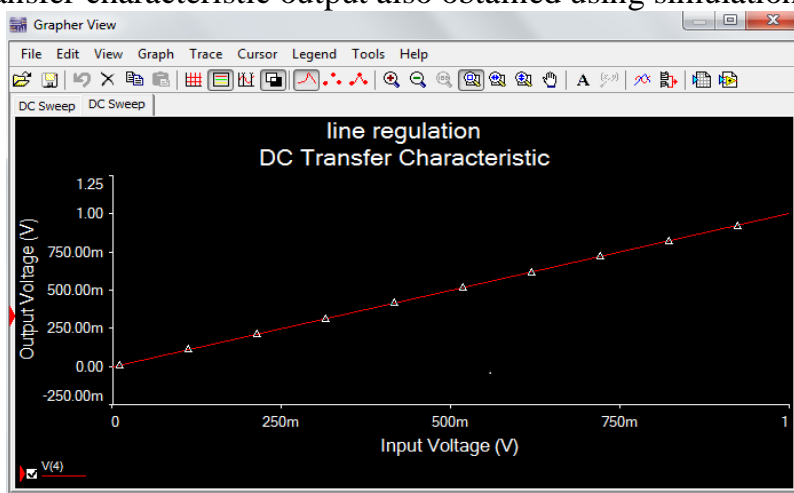

Fig 4:- DC Transfer Characteristics. 


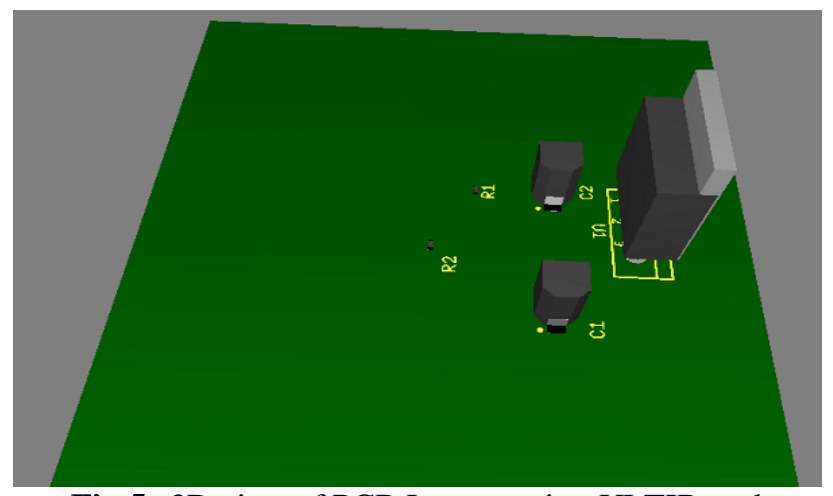

Fig 5:-3D view of PCB Layout using ULTIBoard

The PCB layout diagram was obtained for the simulated output using ULTI Board as shown in fig 5.

\section{Conclusion:-}

The Voltage regulator analysis method based on Multisim is practical and effective. This analysis results can provide some reference for circuit optimization for both Analog and digital circuitdesigners.

\section{References:-}

1. Ren Jun-yuan. The State Transition Analyzing of Flip-flop by Multisim[J]. Experiment Science \& Technology, 2011, 9(1): 53-56.

2. Ren Jun-yuan. An Application of Multisim to the Working Wave AnalyzingofFlip-flop[J]. Modern Electronics Technique, 2010, 33(15): 184-186

3. Ren Jun-yuan. The Exploring and Practice of Cal Teaching Mode Of Electronics Technology Course[J]. Journal of Electrical \&Electronic Education, 2009, 31(4): 99-100.

4. ZHANG ling, LIXin-guang. Multisim Based Schematic Design and Simulation[J] Computer Simulation, 2005, 22(5): 109-152.

5. RENlun-yuan. The Reformation and Practice of Digital Electronics Practice Teaching Mode[J]. Journal ofBohai University (Natural Science Edition), 2010,31(2):165-167.

6. J.Hackworth, R. Jones and W. Stanley, "Increasing productivity and avoiding circuit simulation errors in multisim," in 113th Annual ASEE Conference and Exposition,2006, June 18, 2006 - June 21, 2006, Chicago, IL, Unitedstates, 2006. https://www.sparkfun.com/datasheets/

Components/LM7805.pdf

7. HUANG ZH W. NI Multisimbased computersimulation of electronic circuit design and analysis[M] .Beijing, Electronic Industry Press, 2008. 